\title{
Learning Styles Diagnosis Based on Learner Behaviors in Web Based Learning
}

\author{
Nilüfer Atman ${ }^{1}$, Mustafa Murat Inceoğlu², and Burak Galip Aslan ${ }^{3}$ \\ ${ }^{1}$ Ege University, Department of Computer and Instructional Technologies \\ 35040 Bornova, Izmir, Turkey \\ nilatman@hotmail.com \\ ${ }^{2}$ Ege University, Department of Computer and Instructional Technologies \\ 35040 Bornova, Izmir, Turkey \\ mustafa.inceogluaege.edu.tr \\ ${ }^{3}$ Izmir Institute of Technology, Department of Computer Engineering, \\ 35430 Gulbahce, Urla, Izmir, Turkey \\ bgaslan@ieee.org
}

\begin{abstract}
Individuals have different backgrounds, motivation and preferences in their own learning processes. Web-based systems that ignore these differences have difficulty in meeting learners' needs effectively. One of these individual differences is the learning style. For providing adaptively incorporated learning styles, firstly learning styles of learners have to be identified. There are many different learning models in literature. This study is based on Felder and Silverman's Learning Styles Model and investigates only active/reflective and visual/verbal dimensions of this model. Instead of filling out a questionnaire, learner behaviors are analyzed with the help of literature-based approaches so that learning styles of learners can be detected.
\end{abstract}

Keywords: Felder and Silverman's Index of Learning Styles, Web based Education.

\section{Introduction}

Web-based training with all its potential benefits is growing at a tremendous rate; however most of current systems provide a "one-size-fits-all" approach for the delivery of the material [1]. The fundamental problem is that learners inevitably have diverse backgrounds, abilities and motivation - and hence highly individual learning requirements [2]. These individual differences affect the learning process and are the reason why some learners find it easy to learn in a particular course, whereas others find the same course difficult [3].

As e-Learning environments evolve, learners have become increasingly demanding on personalized learning which allows them to build their own knowledge pathway [4]. Therefore, it is very crucial to provide the different styles of learners with different learning environments that are more preferred and more efficient to them [5]. The 
objective of this study is to develop a literature-based approach for diagnosing learning styles of learners with the help of behavior and action patterns on the user interface. This approach is also evaluated accordingly.

\section{Related Work}

The related studies about this research can be summarized under two main sections; namely, the related studies about learning styles and the related studies about adaptive systems.

\subsection{Learning Styles}

There are many models of learning styles existing in literature. Coffield et al.[6] identified 71 models of learning styles and categorized 13 of them as major models. The term of learning styles is defined as the ways in which an individual characteristically acquires, retains, and retrieves information [7].

In 1988, Felder and Silverman [8] defined five dimensions: perception (sensing/intuitive), input ( visual/auditory), organization (inductive/deductive), processing (active/reflective), understanding (sequential/global). Lately, inductive/deductive was excluded from the model and the dimension of visual/auditory amended as visual/verbal [8].

- Active learners prefer to do something about the outside world, to discuss, comment and test a number of ways when reflective learners prefer make observations, and work on manipulation of information.

- Sensing learners prefer events, data, experiments while, and intuitive learners prefer principles and theories. Sensing learners solve problems in a causal way and are not quite fond of surprises while intuitive learners like to explore new things and do not like repeating stuff.

- Visual learners like pictures, diagrams, flow charts, time charts while verbal learners prefer words and sounds.

- Sequential learners prefer to go step by step; holistic learners can understand better when they see the whole picture [8].

Felder and Soloman developed the Index of Learning Styles (ILS) [9], a 44-item questionnaire, for identifying learning styles based on the Felder and Silverman Learning Style Model. There are four dimensions and 11 items for each dimension and learners have different preferences on each dimension. ILS is a bipolar scale so there can be two answers for each item. Each item scored +1 or -1 and total score of a dimension ranged between -11 and +11 . The advantage of this model is; ILS represents the individuals learning styles as a tendency and there is a third option is that somebody can be equal in both two directions. If the score is between 9-11, it means that there is a strong preference in that dimension; Similarly, if 5-7 then it indicates a moderate preference while 1-3 indicates a balanced preference for that dimension. 
Although there are so many learning styles models in literature such as Kolb, McCarthy, Myers-Briggs and so on, researchers believe that Felder and Silverman Learning Style Model is the most appropriate model for hypermedia courseware and adaptive web based learning systems [10], [11]. Furthermore, Index of Learning Styles is one of the most frequently used instrument and it is especially chosen because of its applicability to online learning and its relevance to the principles of interactive learning systems design [12].

\subsection{Adaptive Systems}

Adaptive hypermedia systems (AHS) build a model of the goals, preferences and knowledge of each individual user, and use this model throughout the interaction with the user, in order to adapt to the needs of that user [13]. The goal of the various Adaptive Educational Hypermedia (AEH) systems that have been developed in recent years has been to avoid the "one size fits all" mentality that is all too common in the design of web-based learning systems [2].

Although there are so many adaptive educational hypermedia systems incorporating learning styles models in literature such as CS383 [10], MANIC [14], IDEAL [16], MASPLANG [17], AHA! [18] etc., the systems that are based on Felder and Silverman's Learning Styles Model are emphasized in this study.

CS383 [10] is providing adaptivity according to sensing/intuitive, visual/verbal, and sequential/global dimensions of Felder and Silverman Learning Styles Model. They underlined that hypermedia system supports both active and reflective dimensions. Hypermedia system enables learners to make choices and participate in learning that supports active learning and give a chance to stop and think for reflective learners.

TANGOW [19] is providing adaptivity based on global/sequential, sensing/intuitive dimensions. Students first fill out ILS and results are pointed to into 3level scale i.e. strong intuitive, balanced learning style or strong sensing learning style. Then balanced learners perform default version, while adaptivity is provided to others. Student model is initialized before the learner behaviors are monitored. According to data from learner behaviors, the information in the student model is updated.

In LSAS [20], sequential/global dimension was studied and adaptivity is provided by two interfaces. Small chunks of information are presented for sequential learners, more navigational freedom is provided for global learners. For assessing the effectiveness of system, first template which is appropriate to the learning styles of learners is presented. The template which is not appropriate to their learning styles is presented afterwards. Test - retest results pointed out there is a significant difference between performances.

One of the studies to diagnose of learning styles belongs to Cha et al. [5]. Firstly, preferences of learners are identified then system adapted interface according to learner's preferences. System is based on Felder and Silverman Learning Styles Model and uses Hidden Markov Model and Decision Trees to extract behavior patterns. Interface is designed with Macromedia Flash and monitored events are recorded. Learning styles are detected by analyzing interface behaviors of learners instead of filling out the Index of Learning Styles. 
Another study analyzing behaviors of learners in Moodle course belongs to Graf [21]. This study is also based on Felder and learning styles model. Behavior patterns are determined according to frequent activities on LMS. This study shows that diverse learning styles of students result in different behaviors in Instructional Management Systems.

Garcia et. al. [22] used Bayesian Networks to detect the learning style of students in a web based education system. The information obtained can then be used by an intelligent agent to provide personalized assistance to students, and delivering teaching material that best fits to students' learning styles.

\section{Methodology}

In this study, a literature-based approach is performed to detect learning styles of learners. The aim of this study is detection of learning styles by analyzing learner behaviors in the web based education system. This study is based on active/reflective and visual/verbal dimensions of Felder and Silverman Learning Styles Model. The topic of teaching "If Clauses" in an ESL course are chosen as subject of this study. A screenshot of web based learning system is given in Fig.1.

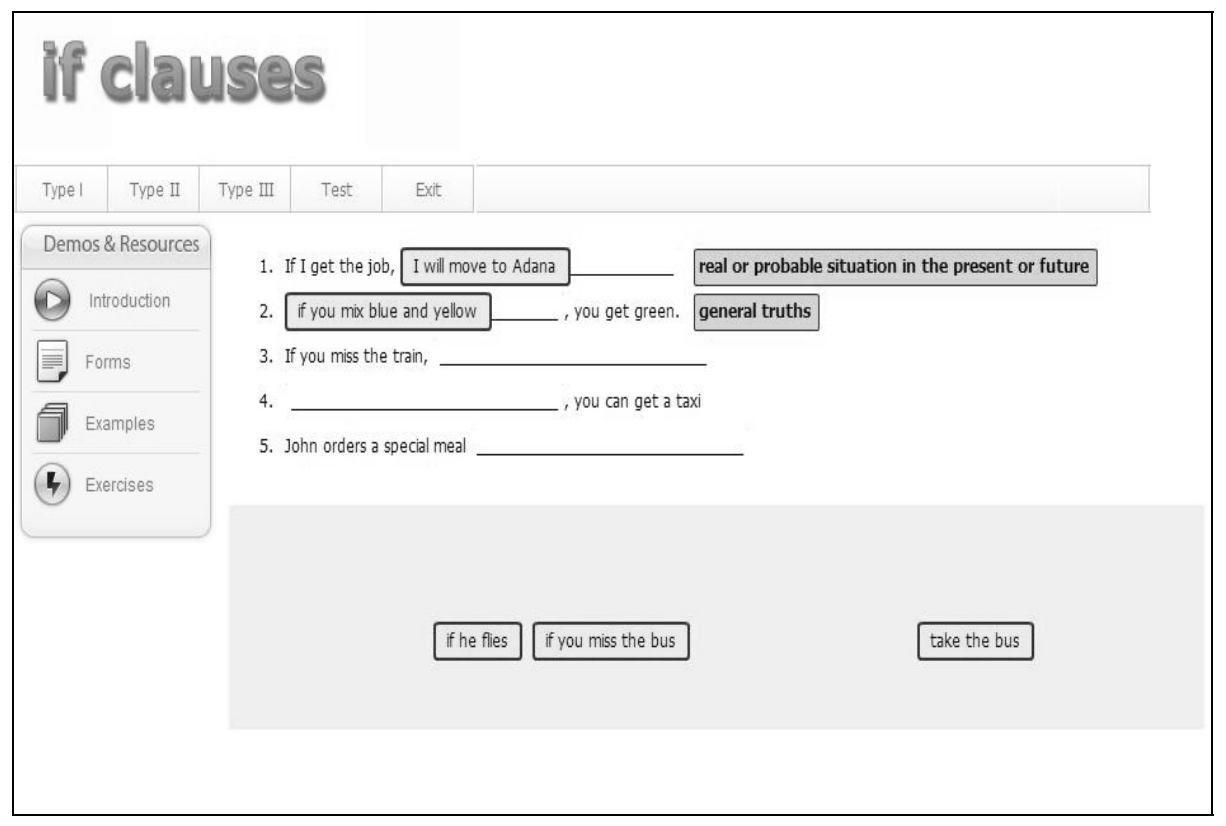

Fig. 1. Screen shot of web based course

In this course, there are four main features, namely; Introduction, Form, Example, Exercise. In Introduction, there are conversations supported by pictures. Form includes the main aspect of subject supported with interactive features. In Example 
section, just like in Introduction part, there are if clauses sentences supported with pictures. Exercises include interactive features and finally in test, there are self assessment questions about the subject.

In this course, each content feature is labeled as VisualActive, VisualReflective, VerbalActive, VerbalReflective. There are 9 Introduction contents labeled as VisualReflective, and 3 form content labeled as VisualActive. 30 example contents that take place are labeled as VisualReflective and finally 6 exercise contents are labeled as active in which one of them is VisualActive and the other is VerbalActive. These labels are determined in parallel to dimension of Felder and Silverman Learning Styles Model. Exercise and form modules have interactive features while Introduction and Example modules have reflective features.

\subsection{Patterns}

For determining the patterns, firstly literature is reviewed, with the help of especially Graf and the other studies, these patterns are defined. Table1. shows relevant patterns for active and visual dimensions.

Table 1. Patterns for [active/reflective] and [visual/verbal] dimensions

\begin{tabular}{ll}
\hline Active/Reflective Dimension & Visual/Verbal Dimension \\
\hline Introduction_visit (-) & Introduction_visit (+) \\
Introduction_stay(-) & Introduction_stay(+) \\
Form_visit(+) & Form_visit(+) \\
Form_stay(+) & Form_stay(+) \\
Example_visit(-) & Example_visit(+) \\
Example_stay(-) & Example_stay(+) \\
Exercise_visit(+) & Exercise1_visit(-) \\
Exercise_stay(+) & Exercise1_stay(-) \\
Test_visit(+) & Exercise2_visit(+) \\
Test_stay(-) & Exercise1_stay(+) \\
Test_Results_View(-) & \\
\hline
\end{tabular}

Introduction_visit is count of visited introduction content of all over the course and Introduction_stay is total time of spent on introduction content. Introduction is labeled as VisualReflective so Active Learners are expected to spend less time. On the other hand Visual learners are supposed to spend more time.

Another module is Form module which has interactive features and labeled as VisualActive. There are drag and drop activities and gives explanations about the subject. Form_visit is number of total visit of individuals and Form_stay is amount of time during the individual stay in the form contents. On that case active and visual learners spend more time on Form module. Just like in Introduction part, Example part is labeled as VisualReflective and expected to spend more time for visual and reflective learners. Example contents are included if clauses sentences supported by pictures. Also example contents could be developed as VerbalReflective, including sentences supported by native speakers talking. Example_stay is total time that 
learner spends in example contents and example_visit is number of visits of example contents.

There are two kinds of exercise modules which are VisualActive and VerbalActive. In VerbalActive exercises are true/false exercises which include sentences that learner reads and listens. VisualActive exercises are drag\&drog exercise where learner chooses from multiple choices.

Test_visit is the count of the questions in test accessed by the learner. According to the Felder and Silverman's Learning Style Model active learners like to do something outside the world [8]. Number of questions performed by learner gives evidence about whether learner active or reflective. Test_stay shows the duration of learner staying in test. Test_Result_View is a pattern that shows the time spent on reviewing the results of test. These patterns give evidence if the learner reflective or not because reflective learners are patient and careful about what they read. They are expected to spend more time in test and test results page.

For detecting learning styles, also thresholds of each pattern must be defined. Garcia and Graf used thresholds for their studies. In this study, these threshold levels are also used but some modifications have to be made because of the nature of the course. The thresholds used in this study are given in Table 2. For example Introduction and form sections of the course are firstly met by learners, and they could visit these features more than others.

Table 2. Thresholds for determined patterns

\begin{tabular}{ll}
\hline Pattern & Thresholds \\
\hline Introduction_stay & $75 \%-125 \%$ \\
Form_stay & $75 \%-100 \%$ \\
Example_stay & $50 \%-75 \%$ \\
Exercise_stay & $50 \%-75 \%$ \\
Test_stay & $50 \%-75 \%$ \\
Test_results & $75 \%-100 \%$ \\
Introduction_visit & $75 \%-100 \%$ \\
Form_Visit & $50 \%-75 \%$ \\
Example_Visit & $25 \%-50 \%$ \\
Exercise_visit & $25 \%-50 \%$ \\
Test_Visit & $25 \%-75 \%$ \\
\hline
\end{tabular}

These thresholds are used as an evaluation criteria for values coming from learner actions. First, the expected time spent on Introduction, Form, Example, Exercise and Test modules and visit frequencies are determined. Then data from learner actions are monitored and values compared using thresholds. For example, the time expected to be spent in Introduction pages is determined at first, then the time spent in Introduction pages extracted from database. The percentage is derived and compared with thresholds. Introduction is labeled as VerbalReflective so active learners are supposed to spend less time. Also there are nine Introduction contents in this course. If the percentage of number of total visits of learner for Introduction content to all of introduction content is between thresholds, this gives us there is balanced evidence. If the 
values are less than threshold, there is a weak preference. Introduction module has reflective features so if the percentage of learner is less than threshold, then it could be said there is a weak evidence for reflective and strong evidence for active learner. Finally if the value is higher than threshold, it could be said there is a strong evidence for reflective and weak evidence for active learner.

The threshold for Introduction_visit is lay between $75 \%$ - \%100. Introduction Part is the firstly met by learners and at visiting $\% 75-\% 100$ of Introduction pages is expected. Visiting more than the threshold gives a hint for a reflective learner. Form part is labeled as VisualActive and gives the main point of subject. Just like in Introduction part, percentages of a learner determined and compared. Thresholds for Introduction and Form contents are higher than Example, Exercise and Test modules because these modules are firstly met by learners. Example_stay, Exercise_stay and Test_stay also Example_visit, Exercise_visit and Test_visit have same thresholds because they are supporting features for subject. Table 2 shows thresholds for determined patterns.

\subsection{Method of Evaluation}

First, the expected time spent on each page is determined. Then, the time that learner spends on each module is recorded. The ratio of these values shows the percentage of each user based on each pattern. If the percentage shows a strong preference for the respecting dimension, then the value of 3 is marked. If the percentage lies between the thresholds then 2 is marked. If there is a weak preference, then 1 is pointed. If there is not any evidence then 0 is pointed.

The average of total hints show the individuals' respected learning style and this value is ranged between 1 and 3 . For scaling the results of the literature-based approach, ranging from 0 to 1 and values of 0.25 and 0.75 were used as thresholds. These thresholds are based on experiments, showing that using the first and last quarter for indicating learning style preferences for one or the other extreme of the respective dimension and using the second and third quarter for indicating a balanced learning style, achieves better results than dividing the range into 3 parts [20]. Also ILS values were mapped again on a 3 -item scale. This evaluation procedure is summarized in Fig. 2.

For measuring how close predicted learning style to the ILS scores, Garcia et al. [22], uses the following formula:

$$
\text { Precision }=\frac{\sum_{i=1}^{n} \operatorname{Sim}\left(L S_{\text {predicted }}, L S_{\text {ILS }}\right)}{n} \cdot 100
$$

The value of $L S_{\text {predicted }}$ refers to predicted learning styles; $L S_{I L S}$ is the value of ILS. If predicted learning styles and ILS values is equal, Sim returns 1 . If one the values is balanced and the other is a preferred learning style of the two poles of that dimension, function then returns 0.5 . Finally if each of two values differs from each other, the function returns 0 . This formula is performed for each student and divided to the number of learners (n). 


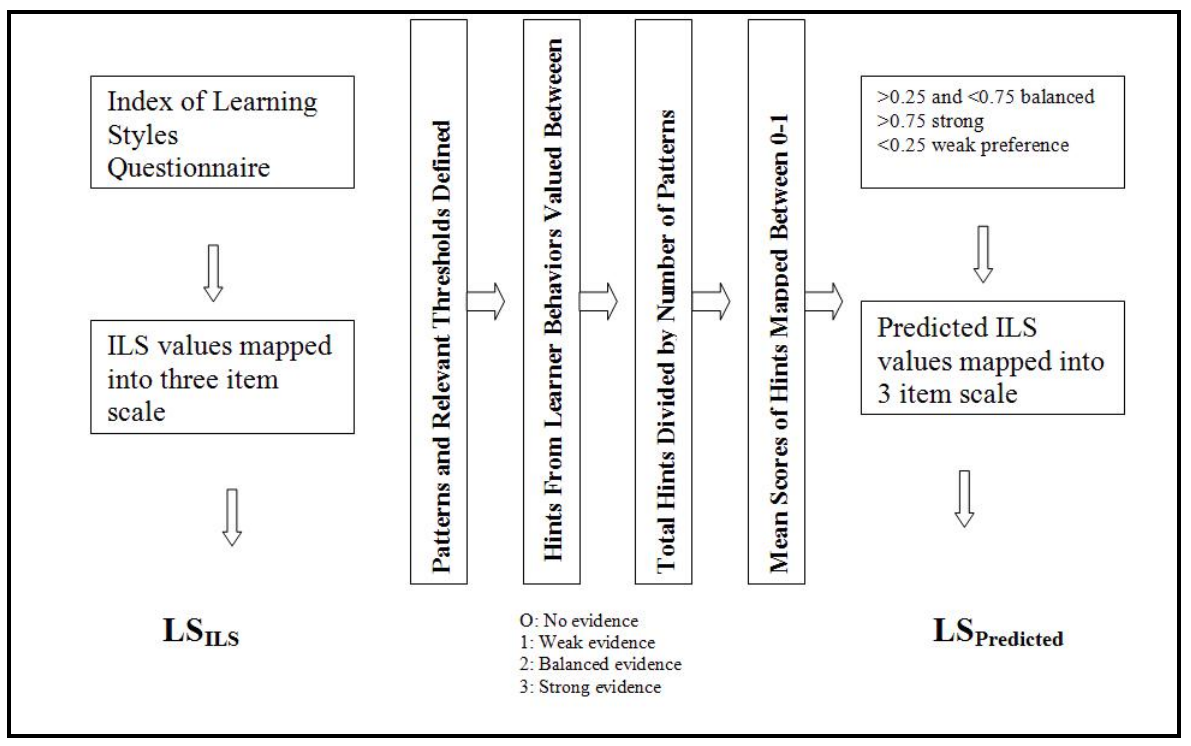

Fig. 2. Overview of evaluation process of automatic detection

\section{Results and Discussion}

Graf's study [20], based on active/reflective, sensing/intuitive and global/sequential dimensions of Felder and Silverman Learning Styles Model and used literature based approach to detect learning styles. Graf [20] analyzed the student behaviors in Moodle software and uses the features of this LMS package. 'Object Oriented Modeling' course continued 7 weeks, data from 75 students analyzed and $79.33 \%$ prediction achievement was found for active/reflective dimension. On the other hand, Garcia et. al. [21], [22], used data-driven approach for diagnosing learning styles. They conducted two experiments. In first experiment 30 students were used to train Bayesian networks and data with 10 students' data were tested, in second experiment 50 students has been used to train Bayesian network and system is tested by 27 students. Result for active/reflective dimension is $62.50 \%$ which is lower then results of the other dimensions. They explained this situation because of the rare use of communication tools such as chat and forum. In this study a web based education system proposed and each module is labeled for their corresponding learning style dimension. This makes analyzing process faster and transportable to other dimensions. Literature-based approach is used. 17 college students behaviors analyzing results show that the prediction achievement is $83.15 \%$. The results of this study belong to a pilot study and also include the detection of visual/verbal dimension. That work is also in progress.

\section{Conclusion}

The study based on Felder and Silverman Learning Styles Model and investigated active/reflective and visual/verbal dimensions. In this study, learner behaviors in a 
web based course are analyzed and learning styles of learners is predicted with the help of literature based approach. For this purpose, learner actions are monitored and stored in database. Five types of content developed, namely; Introduction, Form, Example, Exercise and Test. Each module is labeled such as Visual_Active, Visual_Reflective, Verbal_Active and Verbal_Reflective. This process makes analyzing actions easier and effective. Relevant patterns and thresholds are defined and literature-based approach used for analyzing learner behaviors. To evaluate system effectiveness, learners filled Index of Learning Styles Questionnaire at the beginning of the course. Predicted ILS scores and ILS scores is compared by using the formula developed by Garcia et al. [21], [22]. The very first results show revealing outcomes.

The goal of this study is to detect learning styles automatically instead filling out questionnaires. In this way, students can focus better on course and don't spend extra time and effort for submitting questionnaires. Additionally, course administrators can monitor learning styles of learners. Also in some cases, real behavior and answers for questionnaires do not overlap. This approach is an alternative way to overcome these problems. Besides, this approach provides necessary information for adaptive systems and helps automatically update information in learner model.

\section{References}

1. Liegle, J.O., Janicki, T.N.: The effect of learning styles on the navigation needs of Webbased learners. Computers in Human Behavior 22, 885-898 (2006)

2. Brown, E., Cristea, A., Stewart, C., Brailsford, T.: Patterns in Authoring of Adaptive Educational Hypermedia: A Taxonomy of Learning Styles. Educational Technology \& Society 8(3), 77-90 (2005)

3. Jonassen, D.H., Grabowski, B.L.: Handbook of Individual Differences, Learning, and Instruction. Lawrence Erlbaum Associates, Hillsdale (1993)

4. Sun, L., Ousmanou, K., Williams, S.A.: Articulation of Learners Requirements for Personalised Instructional Design in E-Learning Services. In: Liu, W., Shi, Y., Li, Q. (eds.) ICWL 2004. LNCS, vol. 3143, pp. 427-431. Springer, Heidelberg (2004)

5. Cha, H.J., Kim, Y.S., Park, S.H., Yoon, T.B., Jung, Y.M., Lee, J.-H.: Learning Style Diagnosis Based on User Interface Behavior for the Customization of Learning Interfaces in an Intelligent Tutoring System. In: Ikeda, M., Ashley, K.D., Chan, T.-W. (eds.) ITS 2006. LNCS, vol. 4053, pp. 513-524. Springer, Heidelberg (2006)

6. Coffield, F., Moseley, D., Hall, E., Ecclestone, K.: Should We Be Using Learning Styles? What Research Has to Say to Practice. Learning and Skills Research Centre/University of Newcastle upon Tyne, London (2004)

7. Felder, R.M.: Matters of Style. ASEE Prism 6(4), 18-23 (1996)

8. Felder, R., Silverman, L.: Learning and Teaching Styles. Journal of Engineering Education 94(1), 674-681 (1988)

9. Felder, R.M., Soloman, B.A.: Index of Learning Styles Questionnaire (March 2009), http: / / www. engr.ncsu.edu/learningstyles/ilsweb.html

10. Carver, C.A., Howard, R.A., Lane, W.D.: Addressing Different Learning Styles through Course Hypermedia. IEEE Transactions on Education 42(1), 33-38 (1999)

11. Kuljis, J., Liu, F.: A Comparison of Learning Style Theories on the Suitability for Elearning. In: Hamza, M.H. (ed.) Proceedings of the Iasted Conference on Web Technologies, Applications, and Services, pp. 191-197. ACTA Press (2005) 
12. Baldwin, L., Sabry, K.: Learning Styles For Interactive Learning Systems. Innovations in Education and Teaching International 40(4), 325-340 (2003)

13. Brusilovsky, P.: Methods and techniques of adaptive hypermedia. User Modeling and User-Adapted Interaction 6(2-3), 87-129 (1996)

14. Stern, M.K., Steinberg, J., Lee, H.I., Padhye, J., Kurose, J.: Manic: Multimedia Asynchronous Networked Individualized Courseware. In: Proceedings of the World Conference on Educational Multimedia/Hypermedia and World Conference on Educational Telecommunications (Ed-Media/Ed-Telecom), Calgary, Canada, pp. 1002-1007 (1997)

15. Shang, Y., Shi, H., Chen, S.-S.: An Intelligent Distributed Environment for Active Learning. ACM Journal of Educational Resources in Computing 1(2), 1-17 (2001)

16. Peña, C.-I., Marzo, J.-L., de la Rosa, J.-L.: Intelligent Agents in a Teaching and Learning Environment on the Web. In: Petrushin, V., Kommers, P., Kinshuk, Galeev, I. (eds.) Proceedings of the International Conference on Advanced Learning Technologies, pp. 21-27. IEEE Learning Technology Task Force, Palmerston North (2002)

17. Stash, N., Cristea, A., de Bra, P.: Authoring of Learning Styles in Adaptive Hypermedia: Problems and Solutions. In: Proceedings of the International World Wide Web Conference, pp. 114-123. ACM Press, New York (2004)

18. Carro, R.M., Pulido, E., Rodriguez, P.: Tangow: A Model for Internet-Based Learning. International Journal of Continuing Engineering Education and Lifelong Learning 11(1/2), 25-34 (2001)

19. Bajraktarevic, N., Hall, W., Fullick, P.: Incorporating Learning Styles in Hypermedia Environment: Empirical Evaluation. In: de Bra, P., Davis, H.C., Kay, J., Schraefel, M. (eds.) Proceedings of the Workshop on Adaptive Hypermedia and Adaptive Web-Based Systems, pp. 41-52. Eindhoven University, Nottingham (2003)

20. Graf, S.: Adaptivity in Learning Management Systems Focusing On Learning Styles. Unpublished Ph. D. Thesis (2007)

21. García, P., Amandi, A., Schiaffino, S., Campo, M.: Using Bayesian Networks to Detect Students' Learning Styles in a Web-Based Education System. In: Proceedings of the Argentine Symposium on Artificial Intelligence, Rosario, Argentina, pp. 115-126 (2005)

22. García, P., Amandi, A., Schiaffino, S., Campo, M.: Evaluating Bayesian Networks' Precision for Detecting Students' Learning Styles. Computers \&Education 49(3), 794-808 (2007) 